\title{
Socio-Demographic Profile of HIV-Positive Mothers under the B + Option Followed by Mother-To-Child Transmission Prevention Sites in Bangui City, Central African Republic
}

\author{
Gabouga $F^{1 *}$, Kobangué $L^{1}$, Bangue $C^{2}$, Guéréndo $\mathrm{P}^{1}$, Dibert- \\ Kamba GD1 ${ }^{1}$, Sépou $\mathrm{A}^{3}$ and Grésenguet $\mathrm{G}^{4}$ \\ 1Department of Dermatology-vénérology of Bangui, Central Africa \\ ${ }^{2}$ Pediatric University Hospital Center of Bangui, Central Africa \\ ${ }^{3}$ Obstetrics and Gynecology Department, Bangui Community Hospital, Central Africa \\ ${ }^{4}$ Department of Public Health, Faculty of Health Sciences, Central Africa
}

\section{Research article \\ Volume 4 Issue 1}

Received Date: February 26, 2019

Published Date: March 28, 2019

DOI: $10.23880 /$ cdoaj-16000178

*Corresponding author: Dr Lénguébanga Gabouga Falmata, Department of Dermatovénérologie of Bangui, Central Africa, Tel: (236)75322050; Email: falmatagabouga@ymail.com

\section{Abstract}

Introduction: According to the data of the mother-to-child transmission program with the B + option in 2015, only $28 \%$ of HIV-positive pregnant women benefited from an antiretroviral (ARV) intervention to reduce the risk of mother-tochild Transmission. The aim of this work was to study the demographic profile of HIV-positive mothers under the B + option in the sites of Bangui.

Material and Methods: This was a cross-sectional, retrospective, descriptive study, from January $1^{\text {st }}$ to December 31, 2017 in five sites for the prevention of mother-to-child transmission in the city of Bangui in the Central African Republic.

The study population consisted of all HIV-positive pregnant women followed under the B + option during the year 2017 and meeting the criteria defined during the period of our study.

Results: A total of 293 HIV-positive pregnant women have been identified. The average age was 30 years with extremes of 17 and 43 years. The 25 - 35 year-old pregnants were the most affected, either $61 \%$. The free unions were the most represented $(44.4 \%)$ as well as the unemployed (57\%). Women with primary and secondary levels were the most concerned, respectively $43.7 \%$ and $37.2 \% ; 63.5 \%$ of mothers were diagnosed during pregnancy against $27.6 \%$ before pregnancy and $8.9 \%$ after childbirth.

Conclusion: HIV-positive pregnant women followed under option B + at sites in Bangui were relatively young with a low level of education. They were mostly in a free union and without a job.

Keywords: HIV-positive mothers; HIV; B+ option; epidemiological aspects; Bangui 


\section{Introduction}

In 2013, the World Health Organization (WHO) recommended the use of triple antiretroviral (ART) therapy for all pregnant and breastfeeding women with HIV regardless of CD4 count or clinical stage (Option B +). This option, adopted by 22 countries, including 21 countries in West and Central Africa, has reduced the rate of mother-to-child transmission of HIV by $80 \%$ [1]. The Central African Republic (CAR) is one of the most HIV / AIDS-affected countries in the world with a prevalence of $4 \%$ among adults aged $15-49$ years in 2017 . The epidemic is of a generalized type and constitutes a major problem of public health and development in the country [2]. It is higher in urban areas $(7.9 \%)$ than in rural areas $(2.9 \%)$ for both women $(10.3 \%$ vs. $3.7 \%)$ and men $(4.8 \%$ vs $1.9 \%$ ). On the other hand, young people (aged 15-24) in urban areas are more and more affected (4.4\%) than those in rural areas (1.6\%) [3]. The prevalence also varies between prefectures from one region to another ranging from $1.0 \%$ in Ouham in the north-west to $11.9 \%$ in HautMbomou in the south-east. Despite the progress made in the country in terms of the availability of prevention of mother-to-child transmission (MCTP), MCTP services are only integrated in $47 \%$ of health facilities offering antenatal care (ANC) in the country. Since 2013, the national HIV program has adopted the B+ option protocol implemented in the 156 health facilities that offer MCTP. According to program data in 2015 , only $28 \%$ of HIVpositive pregnant women received an antiretroviral intervention to reduce the risk of Mother-to-Child Transmission in the country [4]. The rate of mother-tochild transmission of HIV has not progressed towards elimination. The mother-to-child transmission rate remains high, $25 \%$ in 2012, $28 \%$ in $2013,20 \%$ in $2014,12 \%$ in 2016, and $6.2 \%$ in 2017. The aim of this work was to study the socio-demographic profile of HIV-positive mothers under $\mathrm{B}+$ option in the Bangui sites in the Central African Republic.

\section{Materials and Methods}

This was a cross-sectional, retrospective, descriptive study from January $1^{\text {st }}$ to December 31, 2017 in five MCTP sites in Bangui City, Central African Republic. The study population consisted of all HIV-positive pregnant women enrolled under the B + option in the course of 2017. The sample size consisted of all HIV-positive pregnant women under the B + option meeting the criteria defined during the period of our study. Have been included in the study, all complete records. Pregnant women under other options were excluded. The variables studied were tracking sites, age, marital status, educational level, occupation, and timing of testing. The data were collected by pre-established questionnaires. They were entered using EpiData software and the statistical analyzes were performed on the EpiData Analysis software. On the ethical front, the data collection sheets were anonymous.

\section{Results}

A total of 293 HIV-positive pregnant women were enrolled under the B + option in the city of Bangui during the study period. Table 1 shows the distribution of women by location of follow-up ( $\mathrm{N}=293)$.

\begin{tabular}{|c|c|c|}
\hline Sites & Number & $\mathbf{\%}$ \\
\hline Community Hospital & 151 & 51,4 \\
\hline Health Center of Bedecombattant & 74 & 25,2 \\
\hline Lakouanga Health Center Camp & 31 & 10,4 \\
\hline Izamo Infirmary & 18 & 6,1 \\
\hline Ouango Health Center & 19 & 6,4 \\
\hline Total & $\mathbf{2 9 3}$ & $\mathbf{1 0 0}$ \\
\hline
\end{tabular}

Table 1: Distribution of pregnant women under option B + according to their place of follow-up ( $\mathrm{N}=293)$.

Table 2 shows the distribution of mothers by age group.

\begin{tabular}{|c|c|c|}
\hline Tranche d'âge & Number & \% \\
\hline 15 to 20 years & 14 & 4,7 \\
\hline 20 to 25 years & 43 & 14,6 \\
\hline 25 to 30 years & 84 & 28,6 \\
\hline 30 to 35 years & 95 & 32,7 \\
\hline 35 to 40 years & 40 & 13,6 \\
\hline 40 years and over & 17 & 5,8 \\
\hline Total & $\mathbf{2 9 3}$ & $\mathbf{1 0 0}$ \\
\hline
\end{tabular}

Table 2: Distribution of mothers by age group.

The average age of the mothers was 30 , with extremes ranging from 17 to 43 years old. The 25 to 35 age groups were the most represented $(179,61.3 \%)$.The distribution of patients by revealed that the unemployed 166 (56.6\%) were more represented followed by traders 59 (20.1\%) and students / students 36 (12.2\%).The distribution of mothers by marital status showed: common-law unions (130 cases or $44.4 \%$ ), single (93 cases or $31.7 \%$ ), married (50 cases or $17.1 \%$ ), divorced (17 cases or $5.8 \%$ ), widows ( 3 cases ie 1\%). The Distribution of women by level of education is shown on table II. 


\section{Clinical Dermatology Open Access Journal}

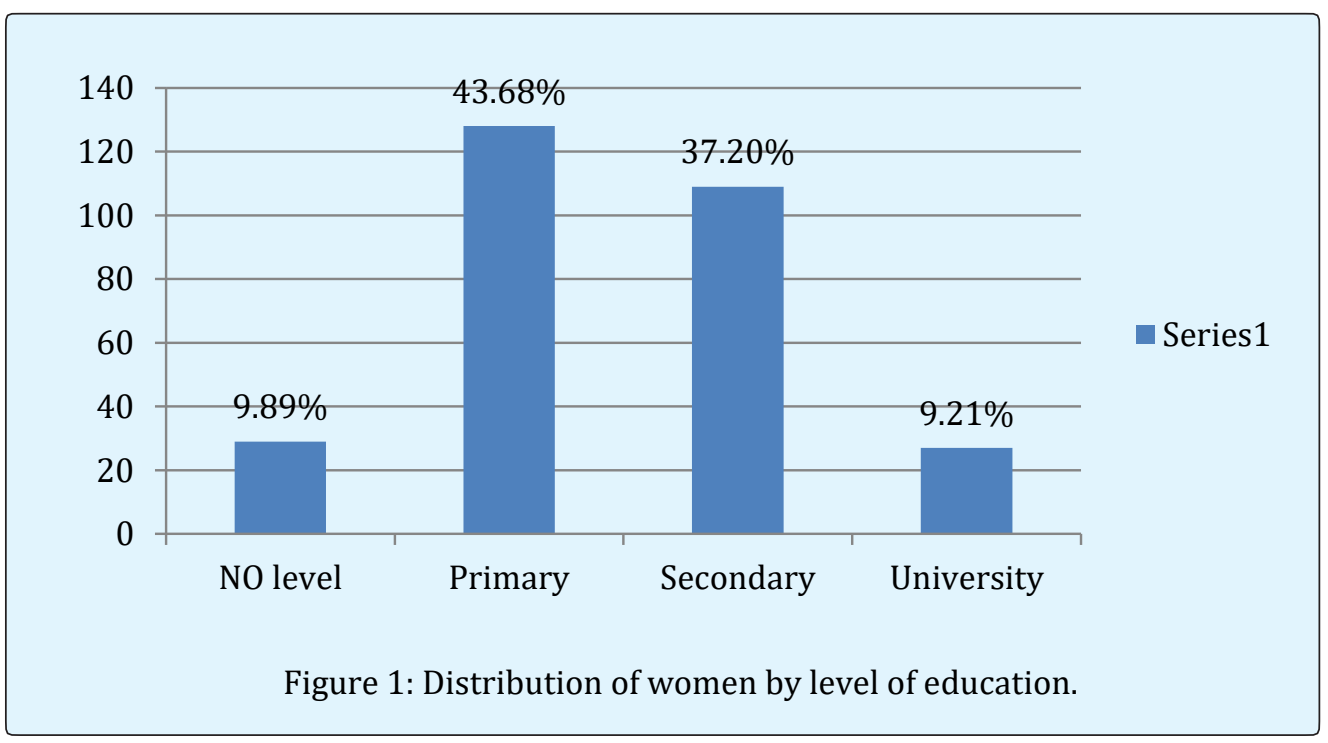

Of the 293 women surveyed, the majority had reached a primary level (128) or $43.7 \%$. The distribution of mothers by time of screening is shown in Table 3 .

\begin{tabular}{|c|c|c|}
\hline Time of screening & Number & \% \\
\hline Before pregnancy & 81 & 27,6 \\
\hline During pregnancy & 186 & 63,5 \\
\hline Afeter delivery & 26 & 8,9 \\
\hline Total & 293 & 100 \\
\hline
\end{tabular}

Table 3: Distribution of mothers by time of screening.

Approximately 186 (or 63.5\%) of the mothers were screened during pregnancy, compared with 81 (27.6\%) before pregnancy and 26 (8.9\%) after delivery.

\section{Discussion}

Our work was aimed at studying the sociodemographic profile of HIV-positive pregnant women followed under B + option in health facilities in Bangui. It was retrospective and some patient informations were not available or misinformed in prenatal consultation records and MCTP files (parent contact information). In addition, the study focused only on five sites of 21 health facilities in the city of Bangui and the latest militarypolitical events were an obstacle to data collection. All this can pose a problem of representativeness. However, our results are exploitable and could constitute our databases. The average age found during our study was 29.5 years. The most represented age group was $25-30$ (43.7\%). This average age was almost the same as that found by Sanon in Senegal [5] and by Rouafi in Mali [6]. The variation in the average age from one country to another could be explained by the weight of culture and lifestyle on sexual behavior. In the Central African Republic, women enter sexual life early, as noted by Sépou, et al. [7] in a study on sexual parameters among central african women in urban areas. Several studies have shown that uneducated women have more health problems than those with a low level of education [6-9]. In fact, the poor understanding of the seriousness of the problems prevents women from making a decision to go to the health facilities as early as possible for prenatal consultation. In our study, the majority of mothers had a primary level followed by the secondary level as demonstrated by a study of the general population of Central Africa [8]. Compared to the time of screening, two-thirds of the mothers were screened during pregnancy. This result was comparable to that of Technau, et al. [10] in South Africa, Dainguy, et al. [11] in Abidjan, where the majority of patients were screened during pregnancy. In Mali, however, Fatoumata Younoussou Maiga [12] obtained respectively 86.1\% before pregnancy, $11.2 \%$ during pregnancy, $2.7 \%$ after delivery and Traoré [13] also observed $60.9 \%$ screening before pregnancy; $19.6 \%$ during pregnancy and 19.6\% after delivery. The difference with Mali is that women screened more before pregnancy than during pregnancy. Screening is the gateway to prevention and care $[14,15]$. For example, mothers who were screened before or during pregnancy were privileged to benefit from interventions to reduce the risk of mother-to-child transmission of HIV. The sensitization campaigns and a better organization of the health care system might be the explanation in our series; and which fits well with the 
national policy of prevention of mother-to-child transmission of HIV that is free and routine in all pregnant women. Mothers screened after delivery had a higher risk $(\mathrm{RR}=0.06$ [0.008-0.524], $\mathrm{P}=0.001)$ of transmitting the HIV virus to their children in our series.

\section{Conclusion}

This work noted that the majority of HIV-positive pregnant women under B + option were in the 25-30 age group, had primary education and were screened during pregnancy. They were mostly in common-law unions and without a profession. Prospective inclusion of patients and interviews at the beginning of their care could help to limit the number of missing data. In addition, the health system will have to intensify the campaign of voluntary testing before pregnancy.

\section{References}

1. Directives de prévention et prise en charge du VIH au Cameroun 2014-2017.

2. Diemer SCH, Ngbalé RN, Longo JDD, Bami dienhot O, Gaunefet CE (2017) Les facteurs de risque de transmission du VIH de la mère à l'enfant à Bangui. Médecine et Sante' Tropicales 27(2): 1-5.

3. Ngbalé RN, Komangoya ND, Diemer H, GoddotNangouma MJC, Gaunefet CE, et al. (2013) Difficultés de la prévention de la transmission du VIH de la mère à l'enfant dans les maternités au sud du Sahara : cas de la maternité d'hôpital communautaire de Bangui. Med d'Afr Noire 60(7): 320-327.

4. Comité National de Lutte Contre le Sida (2011) Cadre Stratégique de Lutte contre le Sida en RCA 2012 2016. Bangui, pp: 135.

5. Sanon DA (2006) Evaluation du statut séroimmunologique des enfants nés de Mères séropositives au VIH suivies au centre de traitement Ambulatoire du service des maladies infectieuses Ibrahima Diop du CHU de Fann de Dakar. Mémoire DEA en Population, Développement et Santé de la Reproduction. Dakar, pp: 63.
6. Rouafi 0 (2005) Suivi des enfants nés de mères séropositives au VIH dans le service de pédiatrie de HGT: bilan de deux années d'activités. pp: 65-82.

7. Le Cœur S, Kanshana S, Jourdain G (2003) Transmission du VIH-1 de la mère à l'enfant et sa prévention. Med Trop 63: 381-390.

8. Sépou A, Yanza MC, Nguembi E, Bangamingo JP, Nali MN (2000) Les Consultations prénatales en zone semi-urbaine Centrafricaine: fréquence, .facteurs influençant, pronostic maternel et néonatal. Med Trop 60(2): 257-261.

9. Coulibaly D (1988) Evaluation de la définition clinique du Sida pédiatrique selon les critères de l'OMS / Bangui. Thèse Med, BKO, pp: 117.

10. Technau KG, Kalk E, Coovadia A, Black V, Pickerill S, et al. (2014) Timing of maternal HIV testing and uptake of prevention of mother-to-child transmission interventions among women and their infected infants in Johannesburg, South Africa. J Acquir Immune Defic Syndr 65(5): e170-e178.

11. Dainguy ME, Folquet AM, Kouadio (2014) Vécu des mères ayant bénéficié de la prévention de transmission Mère-Enfant, PTME dans un centre de référence à Abidjan. Med d'Afr Noire 61(2): 64-70.

12. Fatoumata Younoussou Maiga (2015) Diagnostic précoce de l'infection par le VIH et le devenir des enfants nés de mères séropositives au VIH : expérience du centre d'excellence pédiatrique du CHU Gabriel Touré. Thèse Doct Med Bamako.

13. Traoré MK (2010) Caractéristiques des enfants décédés au cours de leur suivi dans le site PTME du service de pédiatrie du CHU Gabriel Touré. Thèse Med, Bamako.

14. ONUSIDA (2003) Conseil et test VIH volontaires : une voie d'accès à la prévention et aux soins, Genève, pp: 104.

15. Meda N (2010) Prévention de la transmission mèreenfant du VIH : état de lieux et nouvelles stratégies. Transcriptases 143: 1-6. 